УДК 624.131

\title{
ОЦЕНКА ЭРОЗИОННОЙ ОПАСНОСТИ ВОДОСБОРА Р. КАРАБУЛА КРАСНОЯРСКОГО КРАЯ ДЛЯ СТРОИТЕЛЬНОГО ОСВОЕНИЯ
}

\author{
Строкова Людмила Александровна, \\ sla@tpu.ru \\ Национальный исследовательский Томский политехнический университет, \\ Россия, 634050, г. Томск, пр. Ленина, 30.
}

\begin{abstract}
Актуальность. Осуществление хозяйственной деятельности в южнотаежных районах Красноярского края сталкивается с серьезными трудностями в плане почти полного отсутствия актуальной, точной геопространственной информации об опасных процессах и явлениях. Получение такой инфрормации о современном состоянии опасных геологических процессов, характере их пространственного распределения, интенсивности развития является крайне необходимым в процессе хозяйственного освоения региона.

Цель: оконтурить зоны с разной степенью восприимчивости к водной эрозии.

Методы. На первом этапе в ArcGIS подготовлена электронная векторная карта границ водосбора. Далее был разработан перечень геоморфологических, гидрологических, геологических, климатических фракторов, определяющих интенсивность эрозионных процессов. По этим параметрам составлены тематические карты. Затем выполнена оценка веса каждого фактора в возникновении и развитии эрозионных процессов методом анализа иерархий. В результате наложения взвешенных тематических карт по каждому фактору была создана итоговая прогнозная карта, с выделением зон с разной степенью предрасположенности к эрозии.

Результаты работы и область их применения. Наиболее предрасположены к эрозии верховье реки, занятое преимущественно лиственными лесами, средней восприимчивостью характеризуется территория левобережья средней части реки, более освоенной в хозяйственном отношении, наименее предрасположено к эрозии низовье реки, занятое преимущественно лиственнично-сосновыми лесами. Полученные данные рекомендуется использовать при проектировании противоэрозионных мероприятий. Для исследуемой территории была создана иифрровая модель рельефра для инженерно-геологического районирования. Выбраны, рассчитаны и проанализированы основные параметры рельефра, геологии, тектоники, растительного покрова, распределения осадков, определяющие развитие эрозионных процессов. Создана карта инженерно-геологического районирования территории по степени восприимчивости к эрозии.
\end{abstract}

\section{Ключевые слова:}

Эрозия, инженерно-геологическое районирование, цифровая модель рельесра, предрасположенность, метод анализа иерархий, картографирование.

\section{Введение}

Осуществление хозяйственной деятельности в малонаселенных районах затруднено в связи с практически полным отсутствием актуальной, точной геопространственной информации об опасных процессах и явлениях. Получение такой информации о современном состоянии опасных геологических процессов, характере их пространственного распределения, интенсивности развития является крайне необходимым при освоении.

При изучении такого процесса как водная эрозия, принято проводить исследования на бассейновом уровне. По мнению С.В. Пьянкова, А.Н. Шихова и др. [1-3], именно речной бассейн является элементарной геосистемой, в которой отражаются природные закономерности, такие как целостность, уникальность, иерархичность, устойчивость и саморегулирование. Функциональная целостность бассейнов обусловливается существующими вертикальными и горизонтальными связями, а также балансом между ними. $\mathrm{C}$ конца $\mathrm{XX}$ в. созданы различные модели эрозии почвенного покрова, такие как AGNPS (Agricultural Non-Point-Source Pollution Model), WEPP (Water erosion prediction project), USLE (Universal Soil Loss Equation), RUSLE (Revised Universal Soil Loss Equation) и MUSLE (Modification Universal Soil Loss Equation). Результаты моделирования на базе ГИС- технологий были адаптированы для различных речных бассейнов в Бангладеш, Венесуэле, Зимбабве, Индии, Иране, Кении, Марокко, Нигерии, Пакистане, Перу, Сирии, Тунисе, Египте, Эфиопии [4-37].

Для оценки значимости факторов при определении пространственных закономерностей распространения геологических опасностей в зависимости от региональных геологических, морфометрических, климатических, техногенных условий используются различные статистические и детерминированные подходы [38-63]. Методы, основанные на анализе иерархий (АНР), применялись во многих недавних исследованиях $[14,16,21,33,38,42]$ в области инженерной геологии и гидрогеологии, особенно при оценке подверженности территории склоновым процессам, суффозии, загрязнению подземных вод и другим. Однако этот метод все еще является новым для изучения подверженности территории водной эрозии. В настоящем исследовании предпринята попытка оценить восприимчивость территории водосбора реки Карабула к водной эрозии с помощью метода анализа иерархий АНР. Актуальность исследования обусловлена активным освоением данного района в связи со строительством здесь Богучанского алюминиевого завода. Результаты этой работы могут быть полезны лицам, принимающим решения по землепользованию и природообустройству района. 


\section{Характеристика инженерно-геологических} условий территории

Участок расположен в Богучанском районе Красноярского края, в 500 км северо-восточнее г. Красноярск.

В геоморфологическом отношении район исследования располагается в южной части СреднеСибирского плоскогорья на Приангарском плато и представляет собой холмисто-грядовое густо расчлененное плато с абсолютными отметками от 124 до 493 м. По генетическим особенностям рельефа в районе выделяются два основных типа: структурноденудационный и эрозионно-аккумулятивный. В пределах структурно-денудационного рельефа по степени и характеру расчлененности выделяются следующие морфологические типы: горно-холмистый рельеф на ордовикских отложениях; полого-холмистый рельеф на верхнепалеозойских и юрских отложениях; останцовый рельеф на трапповых полях. Эрозионноаккумулятивный рельеф приурочен к долине р. Карабула и ее притоков.

Гидрографическая сеть Богучанского района принадлежит бассейну р. Ангара. Река Карабула берет начало в отрогах Бирюсинского плато (Иркутская область) и впадает в Ангару на 288 км от устья. Длина реки Карабула 212 км, площадь водосбора 5060 км². $^{2}$ Общее падение реки 274 м, средневзвешенный уклон $1,1 \%$. Долина реки в верховьях широкая, V-образной формы, глубоко врезана (120...150 м), склоны высокие, но пологие. Склоны долины террасированы почти на всем протяжении. При выходе из приподнятого участка плато долина расширяется до $8 . .10$ км. Пойма, шириной от 1 до 4 км, прерывистая, местами заболочена, сложена песками и супесями. Русло р. Карабула частично зарастает водной растительностью. Дно илистое и илисто-песчаное. Основными правыми притоками р. Карабула являются: р. Тандакея (длина 165 км), р. Андуиха (143 км), р. Чельчет (119 км), левыми притоками - p. Кунчеть (86 км), p. Кежма (78 км). Ширина долин мелких рек и ручьев, впадающих в Карабулу, обычно не превышает 1 км.

По данным многолетних режимных наблюдений за расходом и уровнем воды в р. Карабула (водопост д. Карабула) за 1951-2013 гг. установлено, что по условиям питания р. Карабула относится к смешанному типу с преобладанием снегового питания $-72 \%$, дождевое питание составляет $21 \%$, питание подземными водами - $7 \%$; уровни воды и расходы в зимний и весенний периоды минимальны, в осенний период достигают средних величин, а во время весеннего паводка, в мае-июне, резко возрастают. Максимальные расходы воды в этот период достигали значений $454 \mathrm{~m} / \mathrm{c}$, при среднем многолетнем значении расходов $11,4 \mathrm{~m} / \mathrm{c}$; среднегодовой модуль стока равен 3,41 л/с с 1 км².

Климат рассматриваемой территории резко континентальный с холодной продолжительной зимой, коротким относительно жарким летом и затяжной дождливой осенью. В любой сезон года возможны резкие изменения погоды, переход от тепла к холоду, резкие колебания температуры воздуха от месяца к месяцу, от суток к суткам и в течение суток. Годовая сумма осадков составляет $400 \ldots 450$ мм, из них жид- ких $-234 \ldots 253$ мм, твердых $-110 \ldots 159$ мм, смешанных - 33...45 мм. Твердые осадки выпадают с октября по апрель, жидкие - с мая по сентябрь. Распределение осадков в течение года происходит неравномерно: на холодный период года приходится $25 . . .40 \%$ годовой суммы осадков, на теплый $-60 \ldots 75 \%$. Месячный максимум осадков приходится на август.

В геологическом строении района принимают участие терригенные отложения нижнего и верхнего палеозоя, мезозоя и рыхлые образования кайнозоя. Палеозойские и мезозойские породы состоят в основном из песчаников, алевролитов, аргиллитов и представлены породами верхоленской $\epsilon_{2} v l$, усть-кутской $\mathrm{O}_{1} u p$, ийской $\mathrm{O}_{1} i s$, бадарановской $\mathrm{O}_{2} b d$, листвяжнинской $\mathrm{C}_{2-3} l s$, рыжкковской $\mathrm{P}_{1} r z$, ингамбинской $\mathrm{P}_{1-2} i$, учамской $\mathrm{T}_{1} u c$, переясловской $\mathrm{J}_{1} p r$, камалинской $\mathrm{J}_{2} k m$ свит. Кайнозойские образования представлены дисперсными связными и несвязными грунтами бельской свиты $\mathrm{Pg}_{3}-\mathrm{N}_{1} b l$ и четвертичными грунтами аллювиального генезиса $\left(\mathrm{aQ}_{\text {III-H }}, \mathrm{a}^{4-5} \mathrm{Q}_{\text {II }}\right)$, приуроченными к долине p. Карабула и еe притоков и делювиальноэлювиального генезиса, приуроченными к водораздельным пространствам и пологим склонам.

Интрузивные образования представлены породами трапповой формации, отнесенной к катангскому комплексу ( $\left.\beta-\pi \beta T_{1} k t\right)$. Слагают они пластовые, реже дайкообразные секущие тела. Пластовые интрузии залегают почти горизонтально и, согласно слоистости отложений ордовика, карбона и перми, прослеживаются по берегам рек без перерыва на десятки километров, повторяя структурные особенности района. Мощность их варьирует от 2 до 160 м. Всего в вертикальном разрезе выделяется до четырех пластовых интрузий. Мощность даек варьирует от 6 до 20 м. Характерной особенностью траппов является их слабая дифференциация. Все они сходны по внешнему облику и минералогическому составу и представлены долеритами, оливиновыми долеритами, габбродолеритами, долерит-порфиритами, микродолеритами и т. п.

В тектоническом отношении территория приурочена к северному борту Мурского прогиба Сибирской платформы. Выделяется два структурных этажа: нижний этаж, сложенный интенсивно дислоцированными верхнепротерозойскими породами фундамента платформы; верхний этаж, представленный палеозойскими, мезозойскими и кайнозойскими отложениями платформенного чехла. Разрывные нарушения в районе подразделяются на разломы донижнетриасового возраста (верхнепермская эпоха), предшествовавшие трапповому магматизму, и мезозойские нарушения.

По схеме гидрогеологического районирования территория работ расположена в пределах гидрогеологической структуры I порядка - Ангаро-Ленского артезианского бассейна в краевой северо-западной части Мурского артезианского бассейна, структуры II порядка. Мурский артезианский бассейн пластовых и блоково-пластовых вод приурочен к крупной тектонической впадине, выполненной отложениями кембрия, ордовика, силура, карбона, перми, триаса и 
юры. По условиям залегания и характеру водовмещающих пород в пределах исследуемой территории выделяются семь водоносных комплексов. Минерализация изменяется от 0,5 до 10 г/л, по химическому составу встречаются воды: гидрокарбонатные, гидрокарбонатные кальциевые, сульфатные кальциевые.
Экзогенные геологические процессы и явления связаны главным образом с деятельностью подземных и поверхностных вод, которые проявились в формировании болот, оврагов, подмыве и обрушении берегов, суффозии и карста. Как правило, болота имеют кочкарный облик с частыми выходами воды на поверхность.
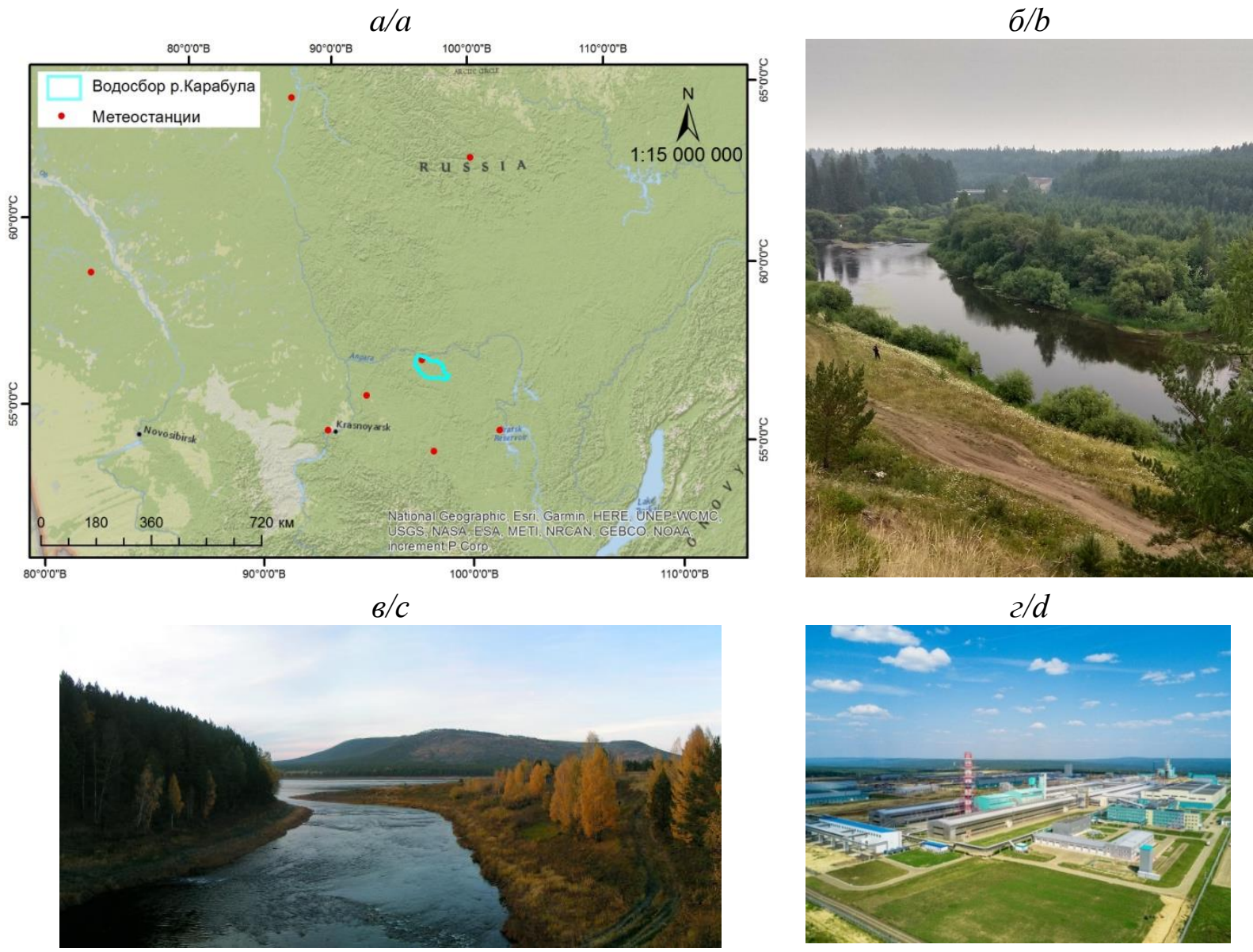

Рис. 1. Положение изучаемой территории (а); река Карабула в средней части (б) и перед впадением в Ангару (в); Богучанский алюминиевый завод возле п. Таежный (2)

Fig. 1. Location of the studied area (a); the Karabula River in the middle (b) and lower (c) parts; the Boguchany Aluminium Smelter/Boguchanskiy Alyuminievy Zavod near place Taezhny $(d)$

\section{Методика работ}

Построение карт восприимчивости осуществляется в следующей последовательности. Вначале выполняется подготовка тематических слоев факторов, обусловливающих возникновение геологического процесса и интенсивности его развития. Затем производится определение веса каждого фактора. В данной работе для определения веса использовался метод анализа иерархий. Далее тематические карты умножаются на соответствующие веса каждого фактора и объединяются в одну средствами наложения. После этого карта дифференцируется на категории с разной степенью восприимчивости в светофорной раскраске, и проводится проверка (рис. 2).

\section{Подготовка тематических карт}

Для построения тематических карт использовались данные открытых источников:
1) метеорологические данные по атмосферным осадкам на 2010-2019 гг. по восьми метеостанциям (их расположение показано на рис. $1, a$ )

2) карта наземного покрова России Центра коллективного пользования «ИКИ-Мониторинг»;

3) цифровая модель рельефа (ЦМР): а) шесть смежных снимков SRTM (n57_e096 1arc v3; n57 e097 1arc v3; n57_e098_1arc_v3; n58_e096_1arc_v3; n58_e097_1arc_v3; n58 e098 1arc v3); б) два смежных снимка Landsat 8 с покрытием 141 колонка 19 ряд и 139 колонка 20 ряд на конец февраля и начало июня 2021 г. (LC08_L1GT_141019_20210225_20210304_02_T2; LC08_L1TP_141019_20210601_20210608_02_T1; LC08_L1TP_139020_20210227_20210304_02_T1; LC08_L1TP_139020_20210603_20210608_02_T1);

4) единая цифровая модель комплекта листа государственной геологической карты О-47 (Братск) масштаба 1:1000000 (ВСЕГЕИ, 2012 г.). 


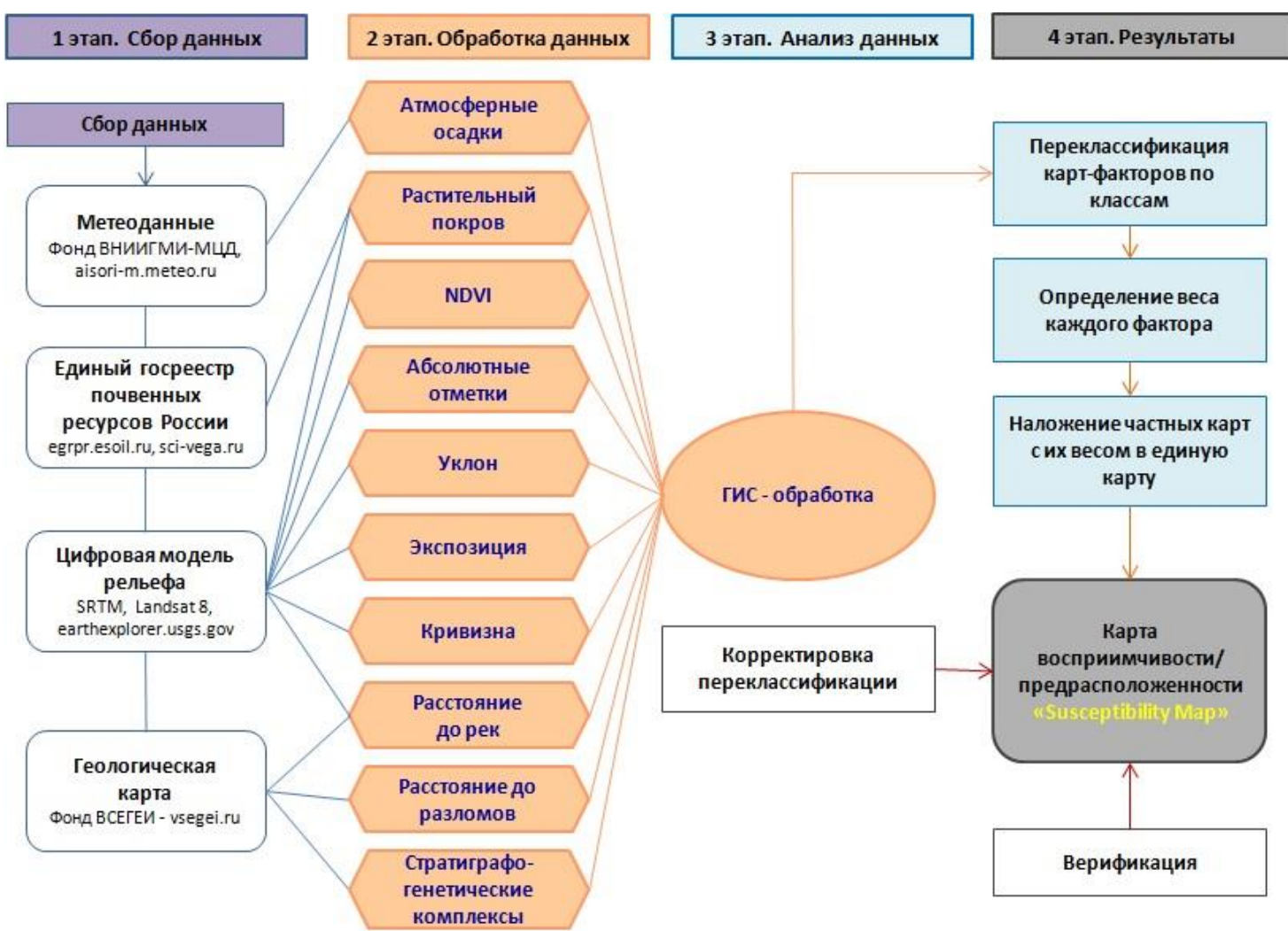

Pис. 2. Схема разработки картьл

Fig. 2. Flowchart of mapping

В табл. 1 представлены перечни тематических слоев, источники получения и способы их ГИСобработки в данном исследовании. Для обработки и анализа использовалась географическая проекция UTM, Zone 47N, и все исходные данные были переведены в эту проекцию.

Таблица 1. Технология создания различных тематических слоев данных

Table 1. Techniques for production of various thematic data layers

\begin{tabular}{|c|c|c|c|}
\hline $\begin{array}{l}\text { Тематический слой } \\
\text { Thematic layer }\end{array}$ & $\begin{array}{l}\text { Источник } \\
\text { Source }\end{array}$ & $\begin{array}{l}\text { Инструменты ГИС-обработки } \\
\text { Tools of Geoprocessing }\end{array}$ & $\begin{array}{l}\text { Использование } \\
\text { Usage }\end{array}$ \\
\hline $\begin{array}{c}\text { Абсолютные отметки } \\
\text { Elevation }\end{array}$ & \multirow{5}{*}{$\begin{array}{c}\text { Радиолокационная топогра- } \\
\text { фическая миссия шаттла } \\
\text { Shuttle Radar Topographic } \\
\text { Mission - SRTM }\end{array}$} & $\begin{array}{c}\text { Классификация ЦМР } \\
\text { Classified from the DEM }\end{array}$ & \multirow{4}{*}{$\begin{array}{l}\text { Характеристика рельефа } \\
\text { Terrain characteristics }\end{array}$} \\
\hline \begin{tabular}{|l|} 
Угол склона \\
Slope angle \\
\end{tabular} & & $\begin{array}{c}\text { Пространственный анализ, Уклон } \\
\text { Spatial Analyst, Slope } \\
\end{array}$ & \\
\hline $\begin{array}{l}\text { Кривизна } \\
\text { Curvature }\end{array}$ & & $\begin{array}{c}\text { Пространственный анализ, Кривизна } \\
\text { Spatial Analyst, Curvature }\end{array}$ & \\
\hline $\begin{array}{l}\text { Экспозиция склона } \\
\text { Slope aspect }\end{array}$ & & $\begin{array}{c}\text { Пространственный анализ, Экспозиция } \\
\text { Spatial Analyst, Aspect } \\
\end{array}$ & \\
\hline $\begin{array}{l}\text { Направление стока } \\
\text { Flow direction }\end{array}$ & & \begin{tabular}{|c|} 
Пространственный анализ, направление стока, \\
кумулятивный сток, границы водосбора \\
Spatial Analyst, Flow direction, Flow \\
Accumulation, Watershed \\
\end{tabular} & $\begin{array}{c}\text { Границы водосбора. } \\
\text { Речная сеть } \\
\text { Catchment boundaries. } \\
\text { Drainage network } \\
\end{array}$ \\
\hline $\begin{array}{l}\text { Расстояние до рек } \\
\text { Distance to streams }\end{array}$ & $\begin{array}{c}\text { Цифровая модель листа О-47 } \\
\text { Digital elevation model } \\
\end{array}$ & \begin{tabular}{|l|} 
Анализ близости, буфер \\
Proximity analysis, buffer
\end{tabular} & $\begin{array}{c}\text { Распределение рек } \\
\text { Drainage network }\end{array}$ \\
\hline $\begin{array}{l}\text { Атмосферные осадки } \\
\text { Mean annual precipitation }\end{array}$ & $\begin{array}{l}\text { ВНИИГМИ-МЦД, } \\
\text { aisori-m.meteo.ru }\end{array}$ & $\begin{array}{c}\text { Пространственный анализ, } \\
\text { интерполяция, крикинг } \\
\text { Spatial analyst, interpolation, kriging }\end{array}$ & $\begin{array}{l}\text { Распределение осадков } \\
\text { Rainfall distribution }\end{array}$ \\
\hline \begin{tabular}{c|} 
Вегетационный \\
индекс NDVI \\
Normalized Difference \\
Vegetation Index
\end{tabular} & $\begin{array}{c}\text { Снимки дистанционного } \\
\text { зондирования Земли } \\
\text { LANDSAT }\end{array}$ & $\begin{array}{l}\text { Калькулятор растра } \\
\text { Raster calculator }\end{array}$ & $\begin{array}{c}\text { Характеристика плотности } \\
\text { растительности } \\
\text { Characteristics of vegetation } \\
\text { density }\end{array}$ \\
\hline $\begin{array}{c}\text { Типизация подстила- } \\
\text { ющей поверхности } \\
\text { Land cover } \\
\end{array}$ & $\begin{array}{l}\text { LANDSAT } \\
\text { sci-vega.ru }\end{array}$ & $\begin{array}{c}\text { Пространственный анализ, многомерность, Не- } \\
\text { контролируемая классификация изокластеров } \\
\text { Spatial Analyst, Iso Cluster }\end{array}$ & $\begin{array}{c}\text { Распределение типов подсти- } \\
\text { лающей поверхности земли } \\
\text { Land cover } \\
\end{array}$ \\
\hline $\begin{array}{l}\text { Геология } \\
\text { Geology }\end{array}$ & $\begin{array}{c}\text { Геологическая карта O-47 } \\
\text { Geological map } \\
\text { vsegei.ru }\end{array}$ & $\begin{array}{l}\text { Переклассификация } \\
\text { Reclassification }\end{array}$ & $\begin{array}{c}\text { Стратиграфо-генетические } \\
\text { комплексы и состав пород } \\
\text { Geological formations and lithology }\end{array}$ \\
\hline $\begin{array}{c}\text { Расстояние до разломов } \\
\text { Distance to faults }\end{array}$ & $\begin{array}{l}\text { Геологическая карта } \\
\text { Geological map }\end{array}$ & $\begin{array}{l}\text { Анализ близости, буфер } \\
\text { Proximity analysis, buffer }\end{array}$ & $\begin{array}{c}\text { Распределение разломов } \\
\text { Faults distribution }\end{array}$ \\
\hline
\end{tabular}




\section{Метод анализа иерархий (АНР)}

Процедура АНР подразделяется на три этапа: определение иерархии целей, критериев и альтернатив; попарное сравнение значимости отдельных частных показателей для каждого уровня иерархии; ранжирование результатов попарного сравнения на общих уровнях иерархии. Первоначально этот подход подразумевает разделение вопроса принятия решений в последовательность важности критериев и альтернатив. В соответствии с важностью каждого фактора назначаются значения предпочтений по шкале Саати [16]. Парные сравнения заключаются в определении степеней доминирования (предпочтения) одного из критериев над другим. На следующем шаге определяются веса приоритетов каждого фактора путем вычисления нормализованного собственного вектора. После получения данных (обработки матриц суждений) следует определить их согласованность. Приемлемым является отношение согласованности (CR) не более $10 \%$.

\section{Результаты}

Наиболее значимыми факторами при оценке геологических процессов являются морфометрические характеристики поверхности.

Абсолютные отметки поверхности получены с цифровой модели рельефа путем классификации растра SRTM (рис. 3,a).

Уклон поверхности закономерно связан с экзогенными процессами и характеристиками ландшафта следующим образом: поверхностный сток и дренирование - чем круче склон, тем интенсивнее поверхностный сток и меньше инфильтрация влаги в почву; интенсивность эрозии растет экспоненциально с увеличением уклона; мощность почвенного профиля на склоне закономерно изменяется в соответствии с уклоном и относительной высотой; количество поступающей солнечной энергии также зависит от уклона, поскольку он определяет угол падения солнечных лучей на земную поверхность (рис. 3,6 ).

Экспозииия поверхности - угол по часовой стрелке между направлением на север и проекцией уклона на горизонтальную плоскость; фиксирует направление (азимут) максимального уклона (градиента) земной поверхности. Экспозиция характеризует основное направление линий тока, т. е. вода (или другой способный к перемещению материал) движется под действием силы тяжести вниз по склону в направлении, которое определяется экспозицией [1]. Эта зависимость положена в основу алгоритма моделирования направления поверхностного стока (Flow direction, рис. 3, 2). Кроме того, экспозиция определяет ориентацию участка по отношению к потоку солнечных лучей и количество радиации, получаемой земной поверхностью, - инсоляцию. Экспозиция существенно влияет на микроклимат участка. В северном полушарии склоны южной экспозиции прогреваются лучше, чем северные склоны. Кроме того, южные склоны суше северных $[2,3]$.
Кривизна склона является основным морфометрическим параметром, рассчитываемым на основе производной второго порядка по ЦМР. Если уклон и экспозиция характеризуют градиент поверхности (его величину и направление), то кривизна фиксирует меру изменений этого градиента, т. е. является градиентом первой производной в заданном направлении. В общем, кривизну в некоторой точке поверхности можно описать как кривизну линии, образованной пересечением земной поверхности с плоскостью определенной ориентации, проходящей через заданную точку. Положительные значения характеризуют выпуклые участки склона, отрицательные - вогнутые (рис. 3, в).

Атмосферные осадки считаются важным фактором эрозии. Там, где скорость выпадения осадков высока, скорость эрозии также возрастает [16]. Тип осадков, их продолжительность и экстремальность в течение сезона и года влияют на процесс эрозии $[2,3]$. На рис. 3, д показано распределение среднегодового количества осадков за десятилетний период в пределах водосборного бассейна р. Карабула, построенное методом крикинга.

Вегетационный индекс NDVI (рис. 3, е) показывает количество фотосинтетически активной биомассы. Открытые земли более уязвимы к эрозии, чем зеленые лесные зоны. Растительность сводит к минимуму потенциал эрозии. Положительные значения $(0,44)$ в NDVI показывают леса, кустарники, в то время как отрицательные значения $(-0,25)$ соответствуют воде, $(-0,5)$ - бетону, асфальту.

Tип растительности (рис. 3, 3). Покров поверхности определяет ее устойчивость к процессу эрозии $[1-3,16]$. Тематический слой получен по снимкам Landsat-8 OLI (от Earth Explorer с разрешением 30 м). Для оценки землепользования использовался алгоритм неконтролируемой классификация изокластеров в ArcGIS, т. к. не было полевой проверки растительного покрова. По рекомендациям [64] для дешифрирования типов растительного покрова были созданы три RGB-композита: два летних композита, состоящих из SWIR1-NIR-RED (синтез 6-5-4 каналов LANDSAT) и NIR-RED-GREEN (красные цвета, синтез 5-4-3 каналов LANDSAT), и один мультисезонный из ближнего инфракрасного (NIR) канала летнего снимка, ближнего инфракрасного (NIR) канала зимнего снимка и красного канала летнего снимка.

В синтезе каналов SWIR1-NIR-RED хвойные леса имеют темно-зеленый цвет, лиственные леса - яркозеленый (салатовый), смешанные леса отличаются различными переходными оттенками, в зависимости от доли хвойных (рис. 4). Смешанный лес со значительным участием широколиственных пород в этом синтезе может иметь слегка желтоватый оттенок, который и будет его отличительным признаком. В синтезе каналов NIR-RED-GREEN (красные цвета) на летнем снимке хвойные леса имеют темно-красный оттенок, мелколиственные леса - ярко-красный, а смешанные леса - переходные цвета. По композиту летнего и зимнего снимка лучше разделяются мелколиственный и смешанный лес. 
$a / a$

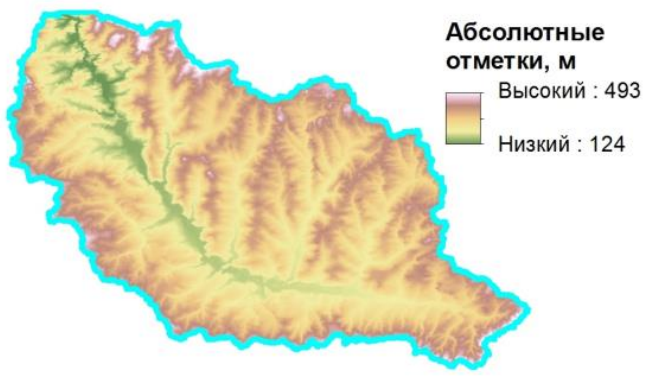

$B / c$

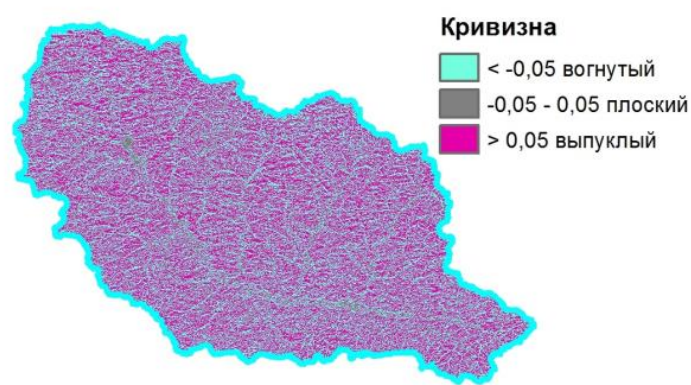

$\partial / e$

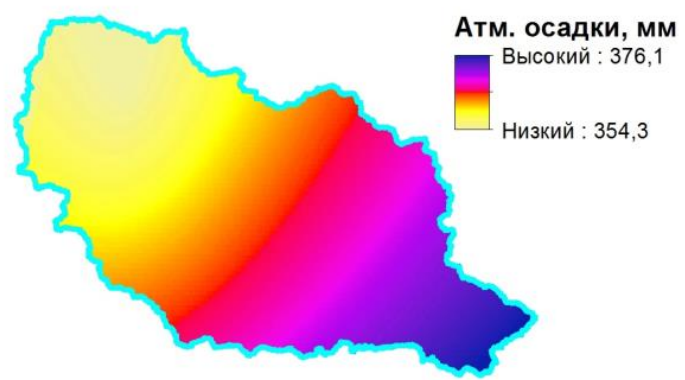

ж/g

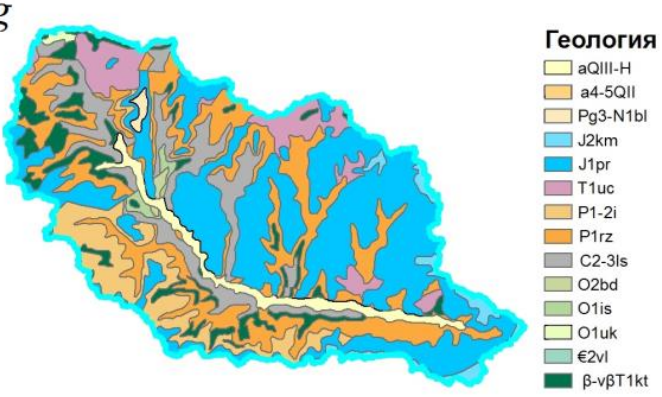

$u / i$

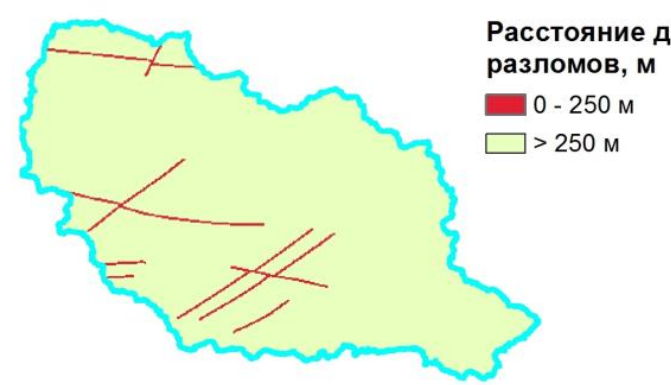

^ $\sigma / b$

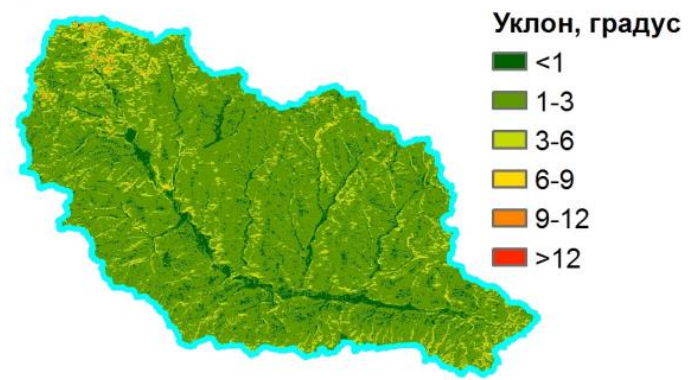

$2 / d$

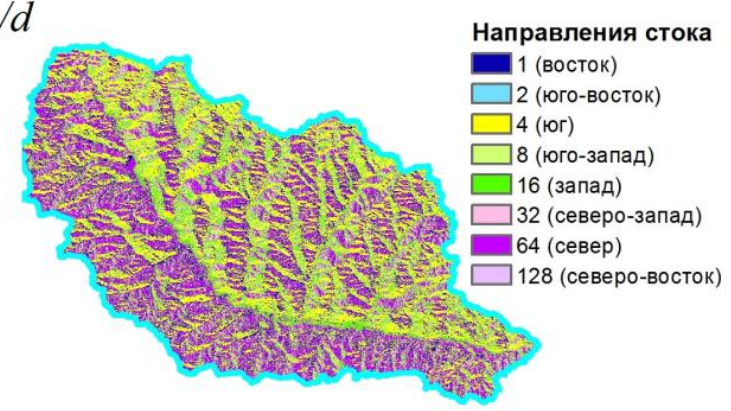

elf

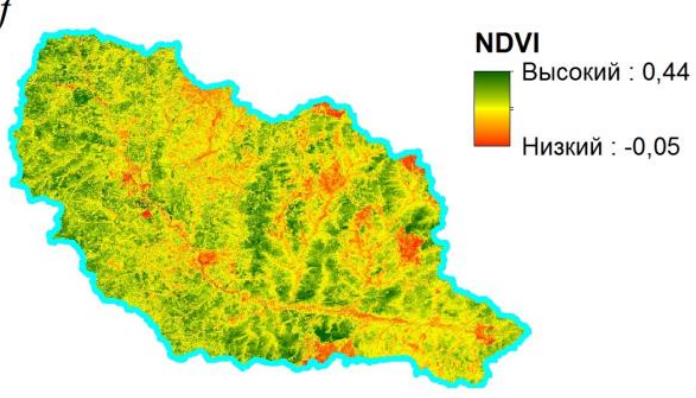

$3 / h$

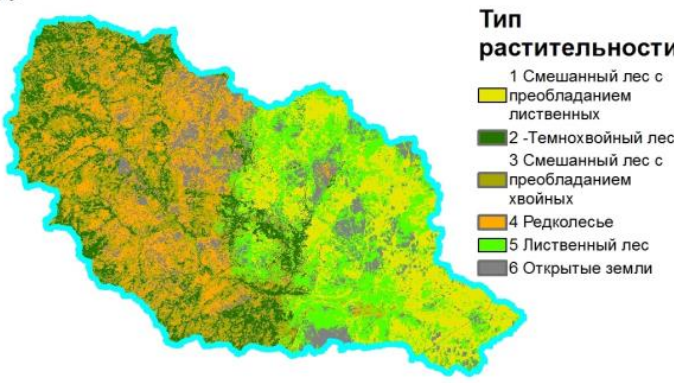

$\kappa / j$

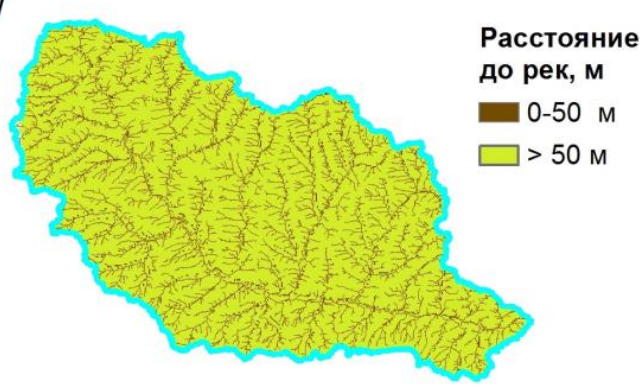

$\begin{array}{llll}1020 & 40 & 60 & 80\end{array}$

$1: 1700000$

Pис. 3. Исходные слои для оченки эрозии

Fig. 3. Data layers for erosion assessment 


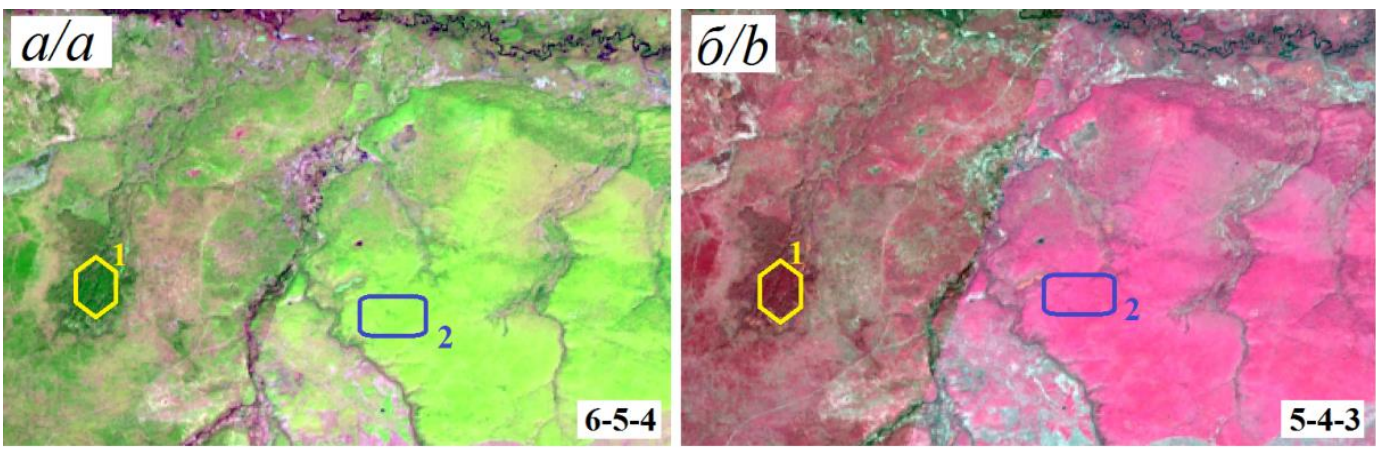

Puc. 4. Ареаль хвойного леса (1), лиственного леса (2) на снимке Landsat-8 летнего периода в синтезе SWIR1-NIRRED (a) и в синтезе NIR-RED-GREEN (б)

Fig. 4. Areals of evergreen forest (1), deciduous forest (2) in the Landsat-8 in summer in the synthesis of SWIR1-NIR-RED (a) and in the synthesis of NIR-RED-GREEN (b)

Выделенные типы растительности на территории уточнены по карте сервиса ВЕГА-PRO Института космических исследований Земли [65].

Геология (рис. 3 , ). Этот тематический слой отражает распространение стратиграфо-генетических комплексов, сложенных породами с характерными физико-механическими и фильтрационными свойствами.

Расстояние до разломов (рис. $3, u)$. Слой отражает тектонические нарушения, разломы, т. к. они способ- ствуют большей скорости инфильтрации осадков, эрозии.

Расстояние до рек (рис. 3, к). Дренажная сеть местности является показателем, объясняющим приуроченность эрозионных участков.

Изучение значимости факторов, обусловливающих эрозию, проводилось методом анализа иерархий (АНР), предложенным Т.Л. Саати в 1970 г. Веса каждого фактора, определенные по методу АНР, представлены в табл. 2.

Таблица 2. Матрица парного сравнения и веса причинных факторов эрозии на основе метода АНР

Table 2. Erosion causative factors' pair-wise comparison matrix and weights based on the AHP method

\begin{tabular}{|c|c|c|c|c|c|c|c|c|c|c|c|}
\hline Критерии /Criteria & $(1)$ & $(2)$ & $(3)$ & $(4)$ & $(5)$ & $(6)$ & $(7)$ & $(8)$ & $(9)$ & $(10)$ & Bec/Weight \\
\hline Угол склона/Slope angle (1) & 1 & 3 & 3 & 3 & 5 & 5 & 5 & 7 & 7 & 7 & 0,25 \\
\hline Геология/Geology (2) & $1 / 3$ & 1 & 1 & 2 & 2 & 2 & 5 & 7 & 7 & 9 & 0,15 \\
\hline Атмосферные осадки/Mean annual precipitation (3) & $1 / 3$ & 1 & 1 & 2 & 3 & 3 & 3 & 5 & 8 & 7 & 0,15 \\
\hline Вегетационный индекс/NDVI (4) & $1 / 3$ & $1 / 2$ & $1 / 2$ & 1 & 3 & 3 & 5 & 5 & 7 & 7 & 0,13 \\
\hline Растительный покров/Land cover (5) & $1 / 5$ & $1 / 2$ & $1 / 3$ & $1 / 3$ & 1 & 3 & 5 & 5 & 9 & 7 & 0,11 \\
\hline Кривизна/Сurvature (6) & $1 / 5$ & $1 / 2$ & $1 / 3$ & $1 / 3$ & $1 / 3$ & 1 & 3 & 5 & 9 & 7 & 0,09 \\
\hline Экспозиция склона/Slope aspect (7) & $1 / 5$ & $1 / 5$ & $1 / 3$ & $1 / 5$ & $1 / 5$ & $1 / 3$ & 1 & 2 & 5 & 5 & 0,05 \\
\hline Расстояние до разломов/Distance to faults (8) & $1 / 7$ & $1 / 7$ & $1 / 5$ & $1 / 5$ & $1 / 5$ & $1 / 5$ & $1 / 2$ & 1 & 2 & 2 & 0,03 \\
\hline Расстояние до рек/Distance to streams (9) & $1 / 7$ & $1 / 7$ & $1 / 8$ & $1 / 7$ & $1 / 9$ & $1 / 9$ & $1 / 5$ & $1 / 2$ & 1 & 2 & 0,02 \\
\hline Абсолютные отметки поверхности/Elevation (10) & $1 / 7$ & $1 / 9$ & $1 / 7$ & $1 / 7$ & $1 / 7$ & $1 / 7$ & $1 / 5$ & $1 / 2$ & $1 / 2$ & 1 & 0,02 \\
\hline
\end{tabular}

Отношение согласованности (Consistency Ratio) $C R=0,058$.

Проведенное сравнение влияния факторов на эрозию показало, что наибольшее значение, или вес, имеет уклон (вес 0,25$)$, также значимыми являются стратиграфо-генетический комплекс пород $(0,15)$, количество атмосферных осадков $(0,15)$ и покров подстилающей поверхности $(0,11)$, менее значимы кривизна $(0,09)$ и экспозиция $(0,05)$ склона. Остальные факторы имеют еще меньший вес $(\leq 0,03)$.

Растровые тематические карты с присвоенными значениями для их классов были умножены на соответствующие веса и суммированы, чтобы получить простую карту, где каждая ячейка имеет определенное значение суммарного индекса восприимчивости к эрозии (рис. 5), проведено классифицирование растра методом «Естественные границы» на пять категорий: очень низкая, низкая, средняя, повышенная и высокая.

\section{Обсуждение результатов исследования}

Для определения взаимосвязи природных и антропогенных факторов с эрозией было рассмотрено 10 факторов.
Ранжирование факторов по методу анализа иерархий (АНР) показало, что наибольшее значение, или вес, имеет уклон, также значимыми являются стратиграфогенетический комплекс (СГК) пород, количество атмосферных осадков и покров подстилающей поверхности, менее значимы кривизна и экспозиция склона, остальные факторы имеют меньший вес. Анализ карты районирования (рис. 5) свидетельствует, что очень низкая степень восприимчивости к эрозии характерна для нижней части водосбора. Здесь в условиях практически сплошной залесенности эрозия возможна в виде небольших ареалов. Средняя часть реки отчетливо делится на две зоны: правобережную, с низкой степенью восприимчивости, и левобережную, с преобладанием средней степени и более освоенную в хозяйственном отношении. Повышенная восприимчивость к эрозии проявляется здесь по зонам разломов и размещения инженерных сооружений. Повышенная и высокая восприимчивость к эрозии, обусловленные изменениями растительного покрова, проявляются в верховьях р. Карабула. 


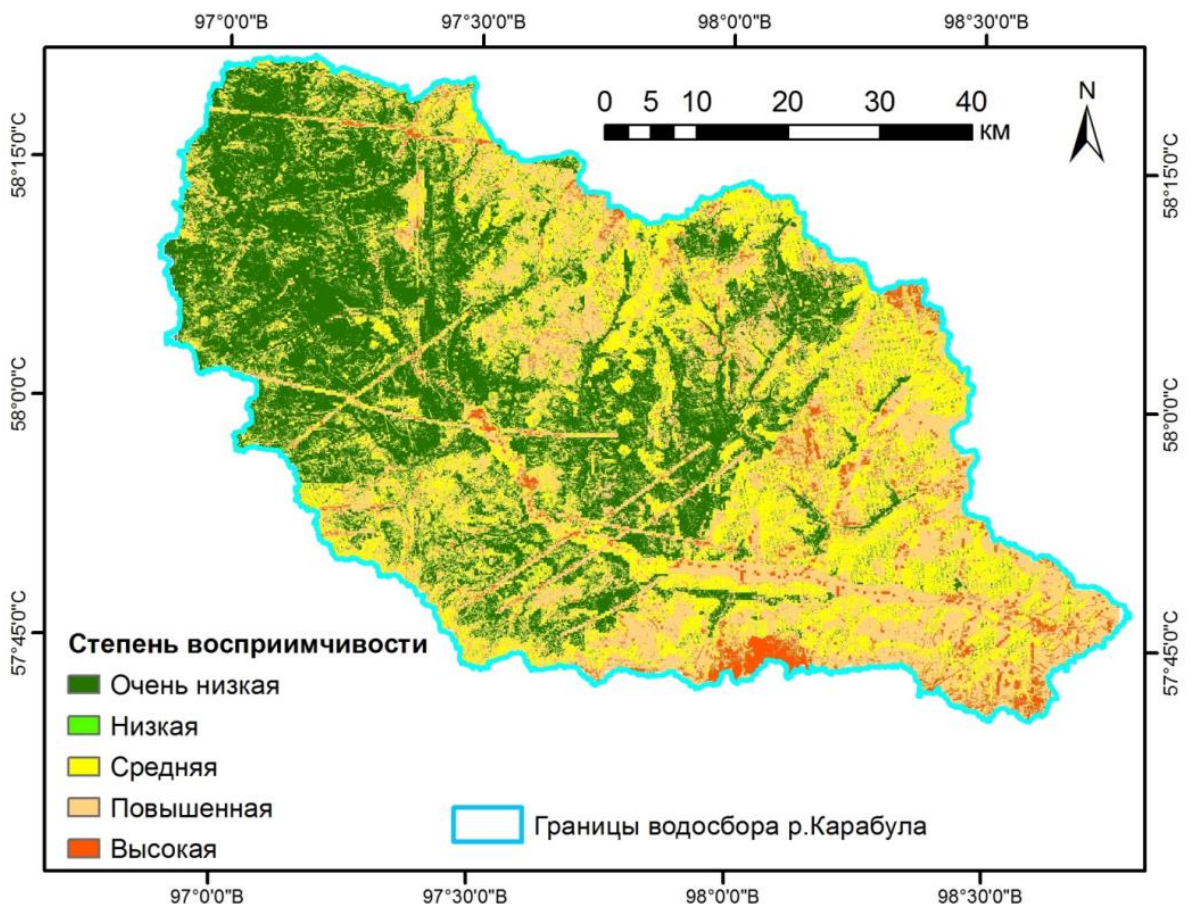

Pис. 5. Карта восприимчивости территории к эрозии с использованием АНР метода

Fig. 5. Erosion susceptibility map of the study area using the AHP model

Несмотря на то, что полученные результаты требуют валидации и возможного уточнения, созданная карта наглядно демонстрирует местоположение эрозионно-опасных участков. Анализ фона, на котором формируется пространственное распределение эрозии в районе, дает основание утверждать, что основными контролирующими факторами процесса является рельеф, гидроклиматические факторы и тип растительности. Следует также отметить, что земледельческая активность здесь слабо развита, так как территория района входит в зону рискованного земледелия.

\section{Выводы}

1. Территория водосбора р. Карабула характеризуется сложными инженерно-геологическими условиями, что является фактором, благоприятствующим развитию опасных геологических процессов и явлений, таких как эрозия, суффозия, заболачивание, карст и другие. Эти процессы осложняют хозяйственное освоение территории и снижают эксплуатационную надежность зданий и сооружений.

\section{СПИСОК ЛИТЕРАТУРЫ}

1. Шихов А.Н., Черепанова Е.С., Пьянков С.В. Геоинформационные системы: методы пространственного анализа. - Пермь: Перм. гос. нац. исслед. ун-т, 2017. - 88 с.

2. Калинин В.Г., Пьянков С.В. Гидрография. Определение гидрографических характеристик рек и их водосборов с применением цифрового картографического моделирования. Пермь: Перм. гос. нац. исслед. ун-т, 2013. - Ч. 2. - 71 с

3. Шихов А.Н., Черепанова Е.С., Пономарчук А.И. Геоинформационные системы: применение ГИС-технологий при решении гидрологических задач: практикум. - Пермь: Перм. гос. нац. исслед. ун-т, 2014. - 91 с.

4. Thakur P.K., Laha C., Aggarwal S.P. River bank erosion hazard study of river Ganga, upstream of Farakka barrage using remote sensing and GIS // Natural Hazards. - 2012. - V. 61. - № 3. -
2. Для анализа пространственных закономерностей, обусловливающих развитие эрозии, выбрано десять факторов: уклон поверхности, экспозиция склона, кривизна, абсолютные отметки поверхности, количество атмосферных осадков, вегетационный индекс NDVI, типы растительности, геологическое строение территории, расстояние до разломов, расстояние до реки.

3. Проведено ранжирование факторов, способствующих развитию эрозии. Значимость факторов оценена методом анализа иерархий.

4. Составлена карта инженерно-геологического районирования территории по степени восприимчивости к эрозии, которую рекомендуется использовать при разработке противоэрозионных мероприятий.

Исследование выполнено в Томском политехническом университете в рамках программы повымения конкурентоспособности Томского политехнического университета (средства ВИУ).

P. 967-987. URL: https://doi.org/10.1007/s11069-011-9944-z (дата обращения 15.07.2021).

5. Soil erosion hazard mapping in central Zab Basin using EPM model in gis environment / H. Shahabi, M. Salari, B.B. Ahmad, A. Mohammadi // International Journal of Geography and Geology. - 2016. - V. 5. - № 11. - P. 224-235.

6. Rahman M.R., Shi Z.H., Chongfa C. Soil erosion hazard evaluation - an integrated use of remote sensing, GIS and statistical approaches with biophysical parameters towards management strategies // Ecological Modelling. - 2009. V. 220. - № 13-14. - P. 1724-1734.

7. Mandal S. Assessing the instability and shifting character of the river bank ganga in Manikchak Diara of Malda district, west Bengal using bank erosion hazard index (BEHI), RS \& GIS // European Journal of Geography. - 2017. - V. 8. - № 4. - P. 6-25. 
8. Mujabar P.S., Chandrasekar N. Coastal erosion hazard an vulnerability assessment for southern coastal Tamil Nadu of India by using remote sensing and GIS // Natural Hazards. - 2013. V. 69. - № 3. - P. 1295-1314.

9. Moses A.N. GIS-RUSLE interphase modelling of soil erosion hazard and estimation of sediment yield for river Nzoia basin in Kenya // J Remote Sens GIS. - 2017. - V. 6. - № 3. - P. 1-13.

10. Andrade O., Kappas M., Erasmi S. Assessment of erosion hazard in Torres municipality of Lara State (Venezuela) based on GIS / Interciencia. - 2010. - V. 35. - № 5. - P. 348-356.

11. Assessment of erosion hazard with the USLE and GIS: A case study of the Upper Ewaso Ng'iro North basin of Kenya / B.M. Mati, R.P. Morgan, F.N. Gichuki, J.N. Quinton, T.R. Brewer, H.P. Liniger // International Journal of Applied Earth Observation and Geoinformation. - 2000. - V. 2. - № 2. - P. 78-86.

12. Winterbottom S.J., Gilvear D.J. A GIS-based approach to mapping probabilities of river bank erosion: regulated River Tummel, Scotland // Regulated Rivers: Research \& Management: an International Journal Devoted to River Research and Management. - 2000. - V. 16. - № 2. - P. 127-140.

13. Potential of weight of evidence modelling for gully erosion hazard assessment in Mbire District-Zimbabwe / F. Dube, I. Nhapi, A. Murwira, W. Gumindoga, J. Goldin, D.A. Mashauri // Physics and Chemistry of the Earth, Parts A/B/C. - 2014. - V. 67. P. $145-152$.

14. Neji N., Ayed R.B., Abida H. Water erosion hazard mapping using analytic hierarchy process (AHP) and fuzzy logic modeling: a case study of the Chaffar Watershed (Southeastern Tunisia) // Arabian Journal of Geosciences. - 2021. - V. 14. - № 13. - P. 1-15.

15. Pambudi A.S., Moersidik S.S., Karuniasa M. Analysis of recent erosion hazard levels and conservation policy recommendations for Lesti Subwatershed, Upper Brantas Watershed // Jurnal Perencanaan Pembangunan: the Indonesian Journal of Development Planning. - 2021. - V. 5. - № 1. - P. 71-93.

16. Soil erosion susceptibility mapping using a GIS-based multicriteria decision approach: case of district Chitral, Pakistan B. Aslam, A. Maqsoom, W.S. Alaloul, M.A Musarat., T. Jabbar, A. Zafar //Ain Shams Engineering Journal. - 2021. - V. 12. № 2. - P. 1637-1649.

17. Ghosh A., Maiti R. Soil erosion susceptibility assessment using logistic regression, decision tree and random forest: study on the Mayurakshi river basin of Eastern India // Environmental Earth Sciences. - 2021. - V. 80. - № 8. - P. 1-16.

18. Mapping soil erosion-prone sites through GIS and remote sensing for the Tifnout Askaoun watershed, southern Morocco / A. Tairi, A. Elmouden, L. Bouchaou, M. Aboulouafa // Arabian Journal of Geosciences. - 2021. - V. 14. - № 9. - P. 1-22.

19. GIS-based hazard and vulnerability assessment of a torrential watershed / P. Kumar, V. Garg, S. Mittal, Y.K. Murthy // Environment, Development and Sustainability. - 2021. - C. 1-31 URL: https://doi.org/10.1007/s10668-021-01476-z (дата обращения 11.07.2021).

20. Agnihotri D., Kumar T., Jhariya D. Intelligent vulnerability prediction of soil erosion hazard in semi-arid and humid region // Environment, Development and Sustainability: a Multidisciplinary Approach to the Theory and Practice of Sustainable Development. 2021. - V. 23. - № 2. - P. 2524-2551.

21. Abdullahi A.I. et al. Application of remote sensing and geoinformatics techniques in erosion mapping and groundwater management in the river Amba Watershed, Central Nigeria / Journal of the Nigerian Society of Physical Sciences. - 2021. V. 3. - № 2. - P. 59-65.

22. Soil erosion modelling using GIS and revised universal soil loss equation approach: a case study of Guna-Tana landscape, Northern Ethiopia / A. Teshome, A. Halefom, M. Teshome, I. Ahmad, Y. Taddele, M. Dananto, P. Szucs // Modeling Earth Systems and Environment. - 2021. - V. 7. - № 1. - P. 125-134.

23. Predicting soil erosion hazard in Lattakia Governorate (W Syria)/ M. Safwan, K. Alaa, A. Omran, B.P. Quoc, T.T.L. Nguyen, N.T. Van, H. Endre // International Journal of Sediment Research. - 2021. - V. 36. - № 2. - P. 207-220.

24. Hoseinzadeh M.M., Barkhordari N. Zonation of bank erosion vulnerability (case study: haft Cheshmeh river, Qazvin) // Physical Geography Research Quarterly. - 2021. - V. 53. - № 1. P. $123-140$.
25. Akbari G., Amani M. Investigation of important and effective factors in soil erosion and sedimentation of Shirin Darreh river using remote sensing and GIS approaches // Iranian journal of Ecohydrology. - 2021. - V. 8. - № 1. - P. 283-293.

26. Kolli M.K., Opp C., Groll M. Estimation of soil erosion and sediment yield concentration across the Kolleru Lake catchment using GIS // Environmental Earth Sciences. - 2021. - V. 80. № 4. - P. 1-14.

27. Kumar N., Singh S.K. Soil erosion assessment using earth observation data in a trans-boundary river basin // Natural Hazards. - 2021. - V. 107. - № 1. - P. 1-34.

28. Batool S., Shirazi S.A., Mahmood S.A. Appraisal of soil erosion through RUSLE model and hypsometry in Chakwal Watershed (Potwar-Pakistan) // Sarhad Journal of Agriculture. - 2021. V. 37. - № 2. - P. 594-606.

29. Applying different resampling strategies in machine learning models to predict head-cut gully erosion susceptibility / F. Wang, M. Sahana, B. Pahlevanzadeh, S.C. Pal, P.K. Shit, M.J. Piran, A. Mosavi // Alexandria Engineering Journal. - 2021. - V. 60. № 6. - P. 5813-5829.

30. Effects of extreme floods on fluvial changes: the Khorramabad River as case study (western Iran) / S. Sharafi, H. Kamangir, S.A. King, R. Safaierad // Arabian Journal of Geosciences. 2021. - V. 14. - № 12. - P. 1-11.

31. Getnet T., Mulu A. Assessment of soil erosion rate and hotspot areas using RUSLE and multi-criteria evaluation technique at Jedeb watershed, Upper Blue Nile, Amhara Region, Ethiopia // Environmental Challenges. - 2021. V. 4. - № 8. - P. 100174

32. Ghosh B., Mukhopadhyay S. Erosion susceptibility mapping of sub-watersheds for management prioritization using MCDM-based ensemble approach // Arabian Journal of Geosciences. - 2021. V. 14. - № 1. - P. 1-18.

33. Ghosh A., Maiti R. Development of new composite index on channel sensitivity using AHP, FR and ensemble model and its application on the Mayurakshi river of Eastern India // International Journal of River Basin Management. - 2021. V 80. - № 8. - P. 1-18. DOI: 10.1080/15715124.2021.1879092

34. Soil conservation assessment via climate change and vegetation growth scenarios in the Nile River basin / H. Liu, Y.X. Liu, W.W. Zhao, D. Peng // Journal of Mountain Science. - 2021. V. 18. - № 4. - P. 863-877.

35. Geologic hazards of the Ocoña river valley, Peru and the influence of small-scale mining / P. Santi, J. Manning, W. Zhou, P. Meza, P. Colque // Natural Hazards. - 2021. - V. 108. - № 9. - P. 2679-2700 URL: https://doi.org/10.1007/s11069-021-04794-7 (дата обращения 15.06.2021).

36. Gebreegziabher T., Suryabhagavan K.V., Kumar Raghuvanshi T. WebGIS-based decision support system for soil erosion assessment in Legedadi watershed, Oromia Region, Ethiopia // Geology, Ecology, and Landscapes. - 2021. - P. 1-18. URL: https://doi.org/10.1080/24749508.2021.1924441 (дата обращения 11.07.2021).

37. Khademalrasoul A., Amerikhah H. Assessment of soil erosion patterns using RUSLE model and GIS tools (case study: the border of Khuzestan and Chaharmahal Province, Iran) // Modeling Earth Systems and Environment. - 2021. - V. 7. - № 2. - P. 885-895.

38. Ghorbanzadeh $\mathrm{O}$, Feizizadeh $\mathrm{B}$., Blaschke T An interval matrix method used to optimize the decision matrix in AHP technique for land subsidence susceptibility mapping. Environmental Earth Sciences. - 2018. - V. 77. - Article number 584.

39. Landslide susceptibility mapping for Austria using Geons and optimization with the Dempster-Shafer theory / T. Gudiyangada Nachappa, S. Tavakkoli Piralilou, O. Ghorbanzadeh, H. Shahabi, T. Blaschke // Applied Sciences. - 2019. - V. 9 (24). Article number 5393

40. Comparison and validation of per-pixel and object-based approaches for landslide susceptibility mapping / T. Gudiyangada Nachappa, S. Kienberger, S.R. Meena, D. Hölbling, T. Blaschke // Geomatics, Natural Hazards and Risk - 2020 - V. 11. - № 1. P. 572-600.

41. Estimating the quality of landslide susceptibility models / F. Guzzetti, P. Reichenbach, F. Ardizzone, M. Cardinali, M. Galli // Geomorphology. - 2006. - V. 81. - P. 166-184.

42. Ivanova E. Landslide susceptibility mapping using Frequency Ratio and Analytic Hierarchy Process (AHP): comparative study 
of two areas in Bulgaria // Proceedings of the International Conference Analysis and Management of Changing Risk for Natural Hazards. - Padua, Italy, 18-19 November, 2014. P. AP23-1-AP23-9.

43. Rasyid A.R., Bhandary N.P., Yatabe R. Performance of frequency ratio and logistic regression model in creating GIS based landslides susceptibility map at Lompobattang Mountain, Indonesia. Geoenvironmental Disasters. - 2016. - V. 3 . Article number 19.

44. Optimizing the frequency ratio method for landslide susceptibility assessment: a case study of the Caiyuan Basin in the southeast mountainous area of China / Y.X. Zhang, H.X. Lan, L.P. Li, Y.M. Wu, J.H. Chen, N.M. Tian // Journal of Mountain Science. 2020. - Vl. 17. - Article number 2

45. Spatial distribution and susceptibility zoning of geohazards along the Silk Road, Xian-Lanzhou / J. Zhuang, J. Peng, X. Zhu, W. Li, P. Ma, T. Liu // Environmental Earth Sciences. - 2016. - V. 75. Article number 711 .

46. Wang M., Qiao J., He S. GIS-based earthquake-triggered landslide hazard zoning using contributing weight model // Journal of Mountain Science. - 2010. - V. 7. - P. 339-352. DOI 10.1007/s11629-010-2054-7

47. Cheng J., Tao J.P. Fuzzy comprehensive evaluation of drought vulnerability based on the analytic hierarchy process - an empirical study from Xiaogan City in Hubei Province // Agriculture and Agricultural Science Procedia. - 2010. - V. 1. P. 126-135.

48. Classification of the type of eco-geological environment of a coal mine district: a case study of an ecologically fragile region in Western China / Z. Yang, W. Li, Y. Pei, W. Qiao, Y. Wu // Journal of Cleaner Production. - 2018. - V. 174. - P. 1513-1526.

49. Liu S., Li W. Indicators sensitivity analysis for environmental engineering geological patterns caused by underground coal mining with integrating variable weight theory and improved matter-element extension model // Science of the Total Environment. - 2019. - V. 686. - P. 606-618

50. Liu S., Li W., Wang Q. Zoning method for environmental engineering geological patterns in underground coal mining areas // Science of the Total Environment. - 2018. - V. 634. - P. 1064-1076

51. Строкова Л.А., Ежкова А.В., Леонова А.В. Применение линеаментного анализа для оценки карстоопасности при проектировании магистрального газопровода в южной Якутии // Известия Томского политехнического университета. Инжиниринг георесурсов. - 2020. - Т. 331. - № 11. - С. 117-126.

52. Строкова Л.А. Районирование участков строительства прудовотстойников Эльгинского каменноугольного месторождения в Якутии» Якутии // Известия Томского политехнического университета. Инжиниринг георесурсов. - 2021. - Т. 332. - № 1. C. $97-106$.

53. Опыт инженерно-геологического районирования по несущей способности грунтов промплощадки Эльгинского ГОК в Якутии / Л.А. Строкова, С.А. Дмитриева, Н.В. Осьмушкина, А.В. Осьмушкин // Известия Томского политехнического университета. Инжиниринг георесурсов. - 2019. - Т. 330. - № 2. C. $175-185$.

54. Strokova L. Recognition of geological processes in permafrost conditions // Bulletin of Engineering Geology and the Environment. - 2019. - V. 78 (8). - P. 5517-5530.
55. Фи Х.Т., Строкова Л.А. Типизация грунтовых толщ территории города Ханой (Вьетнам) при изучении оседания земной поверхности из-за извлечения подземных вод // Известия Томского политехнического университета. Инжиниринг георесурсов. - 2017. - Т. 328. - № 4. - С. 6-17.

56. Строкова Л.А., Галеева Э.И., Леонова А.В. Районирование инженерно-геокриологических условий трассы трубопровода на Восточно-Мессояхском нефтегазоконденсатном месторождении // Известия Томского политехнического университета. Инжиниринг георесурсов. - 2020. - Т. 331. - № 10. - С. 14-22.

57. Strokova L.A., Teterin E. A. Identification, diagnosis and ranking of risks of geohazard in pipeline and urbanized territories // IOP Conference Series: Earth and Environmental Science. - 2016. V. 43. -6 p. - Article number 012051.

58. Строкова Л.А., Надеждина Ю.Ю. Типизация инженерногеологических условий территории трассы проектируемой железной дороги Элегест-Кызыл-Курагино // Известия Томского политехнического университета. Инжиниринг георесурсов. -2020 . - Т. 331. - № 2. - С. 64-77.

59. Строкова Л.А., Епифанова Е.А., Коржнева Т.Г. Численный анализ поведения основания опоры моста на старой железнодорожной линии // Известия Томского политехнического университета. Инжиниринг георесурсов. - 2017. - Т. 328. - № 5. C. $125-139$

60. Епифанова Е.А., Строкова Л.А. Оценка деформаций исторического здания в Томске с помощью комплексного подхода, основанного на сочетании наземного лазерного сканирования и конечно-элементного моделирования // Известия Томского политехнического университета. Инжиниринг георесурсов. 2018. - T. 329. - № 5. - C. 27-41.

61. Епифанова Е.А., Строкова Л.А. Анализ деформаций прожекторной мачты при помощи наземного лазерного сканирования и метода конечных элементов // Известия Томского политехнического университета. Инжиниринг георесурсов. 2019. - Т. 330 - № 5. - С. 7-17.

62. Сахаровский А.В, Строкова Л.А., Определение устойчивости оползневого склона при проектировании моста через р. Пошнарку в Чувашии // Известия Томского политехнического университета. Инжиниринг георесурсов. - 2020. - Т. 331. № 1. - C.125-134.

63. Оценка инженерно-геокриологических условий Берегового нефтегазоконденсатного месторождения / Л.А. Строкова, Д.В. Пургина, Э.И. Галеева, А.Н. Курчатова // Известия Томского политехнического университета. Инжиниринг георесурсов. - 2018. - Т. 329. - № 12. - С. 6-19.

64. Тематическое дешифрирование и интерпретация космических снимков среднего и высокого пространственного разрешения / А.Н. Шихов, А.П. Герасимов, А.И. Пономарчук, Е.С. Перминова. - Пермь: Пермский государственный национальный исследовательский университет, 2020. 191 c. URL: http://www. psu.ru/files/docs/science/books/uchebnie-posobiya/shikhovgerasimov-ponomarchuk-perminova-tematicheskoe-deshifrovaniei-interpretaciya-kosmicheskih-snimkov.pdf (дата обращения 15.07.2021).

65. ВЕГА-PRO спутниковый сервис анализа вегетации. URL: http://sci-vega.ru/maps/ (дата обращения 27.07.2021).

Поступила 30.07.2021 г.

\section{Информация об авторах}

Строкова Л.А., доктор геолого-минералогических наук, профессор отделения геологии Инженерной школы природных ресурсов Национального исследовательского Томского политехнического университета 
UDC 624.131

\title{
ASSESSMENT OF EROSION HAZARD OF THE WATERSHED OF THE KARABULA RIVER IN THE KRASNOYARSK KRAI FOR CONSTRUCTION DEVELOPMENT
}

\author{
Lyudmila A. Strokova, \\ sla@tpu.ru
}

National Research Tomsk Polytechnic University, 30, Lenin avenue, Tomsk, 634050, Russia.

\begin{abstract}
The relevance. The implementation of economic activities in the southern taiga regions of the Krasnoyarsk Krai faces serious difficulties in terms of almost complete lack of up-to-date, accurate geospatial information about hazardous processes and phenomena. Obtaining such information about the current state of dangerous geological processes, the nature of their spatial distribution, the intensity of development is extremely necessary in the process of economic development of the region.

The main aim of the research is to outline zones with different degrees of susceptibility to water erosion.

Methods. Firstly, we prepared the electronic vector map of the catchment boundaries. Secondly, we developed the list of geomorphological, hydrological, geological, and climatic factors determining the intensity of erosion processes. We compiled thematic maps according to these parameters. Thirdly, we carried out the assessment of the weight of each factor in the occurrence and development of erosion processes by the Analytical hierarchy process. Finally, as a result of the overlay of weighted thematic maps for each factor, we created the final forecast map with the allocation of zones with different degrees of susceptibility to erosion.

Results. The upper reaches of the river, occupied mainly by deciduous forests, are the most prone to erosion, the territory of the left bank of the middle part of the river is characterized by moderate susceptibility, the lower reaches of the river, occupied mainly by larch-pine forests, are the least prone to erosion. The obtained data is recommended to be used in the design of anti-erosion measures. A digital relief model for engineering and geological zoning was created for the studied territory. The main parameters of the relief, geology, tectonics, vegetation, land cover, precipitation distribution that determine the development of erosion processes are selected, calculated and analyzed. A map of the engineering and geological zoning of the territory according to the degree of susceptibility to erosion was developed.
\end{abstract}

\section{Key words:}

Erosion, engineering geological zoning, digital elevation model, susceptibility, analytical hierarchy process, mapping.

The research was carried out at Tomsk Polytechnic University within the Program of Tomsk Polytechnic University Competitiveness Enhancement (VIU funds).

\section{REFERENCES}

1. Shikhov A.N., Cherepanova E.S., Pyankov S.V. Geoinformatsionnye sistemy: metody prostranstvennogo analiza [Geoinformation systems: methods of spatial analysis]. Perm, Perm State National University, 2017. 88 p.

2. Kalinin V.G., Pyankov S.V. Gidrografiva. Opredelenie gidrograficheskikh kharakteristik rek $i$ ikh vodosborov s primeneniem tsifrovogo kartograficheskogo modelirovaniya [Hydrography. Determination of hydrographic characteristics of rivers and their catchments using digital cartographic modeling]. Perm, Perm State National University, 2013. P. 2, 71 p.

3. Shikhov A.N., Cherepanova E.S., Ponomarchuk A.I Geoinformatsionnye sistemy: primenenie GIS-tekhnologiy pri reshenii gidrologicheskikh zadach [Geoinformation systems: the use of GIS technologies in solving hydrological problems]. Perm, Perm State National University, 2014. 91 p.

4. Thakur P.K., Laha C., Aggarwal S.P. River bank erosion hazard study of river Ganga, upstream of Farakka barrage using remote sensing and GIS. Natural Hazards, 2012, vol. 61, pp. 967-987. Available at: https://doi.org/10.1007/s11069-011-9944-z (accessed 15 July 2021).

5. Shahabi H., Salari M., Ahmad B.B., Mohammadi A. Soil erosion hazard mapping in central Zab Basin using EPM model in gis environment. International Journal of Geography and Geology, 2016, vol. 5, no. 11, pp. 224-235.

6. Rahman M.R., Shi Z.H., Chongfa C. Soil erosion hazard evaluation - an integrated use of remote sensing, GIS and statistical approaches with biophysical parameters towards management strategies. Ecological Modelling, 2009, vol. 220, no. 13-14, pp. 1724 1734.

7. Mandal S. Assessing the instability and shifting character of the river bank Ganga in Manikchak Diara of Malda district, west Bengal using bank erosion hazard index (BEHI), RS \& GIS. European Journal of Geography, 2017, vol. 8, no. 4, pp. 6-25.
8. Mujabar P.S., Chandrasekar N. Coastal erosion hazard and vulnerability assessment for southern coastal Tamil Nadu of India by using remote sensing and GIS. Natural Hazards, 2013, vol. 69, no. 3, pp. $1295-1314$.

9. Moses A.N. GIS-RUSLE interphase modelling of soil erosion hazard and estimation of sediment yield for river Nzoia basin in Kenya. J Remote Sensing \& GIS, 2017, vol. 6, no. 3, pp. 1-13.

10. Andrade O., Kappas M., Erasmi S. Assessment of erosion hazard in Torres municipality of Lara State (Venezuela) based on GIS. Interciencia, 2010, vol. 35, no. 5, pp. 348-356.

11. Mati B.M., Morgan R.P., Gichuki F.N., Quinton J.N., Brewer T.R., Liniger H.P. Assessment of erosion hazard with the USLE and GIS: a case study of the Upper Ewaso Ng'iro North basin of Kenya. International Journal of Applied Earth Observation and Geoinformation, 2000, vol. 2, no. 2, pp. 78-86.

12. Winterbottom S.J., Gilvear D.J. A GIS-based approach to mapping probabilities of river bank erosion: regulated River Tummel, Scotland. Regulated Rivers: Research \& Management: an International Journal Devoted to River Research and Management, 2000, vol. 16, no. 2, pp. 127-140.

13. Dube F., Nhapi I., Murwira A., Gumindoga W., Goldin J., Mashauri D.A. Potential of weight of evidence modelling for gully erosion hazard assessment in Mbire District - Zimbabwe. Physics and Chemistry of the Earth, Parts A/B/C, 2014, vol. 67, pp. 145-152.

14. Neji N., Ayed R.B., Abida H. Water erosion hazard mapping using analytic hierarchy process (AHP) and fuzzy logic modeling: a case study of the Chaffar Watershed (Southeastern Tunisia). Arabian Journal of Geosciences, 2021, vol. 14, no. 13, pp. 1-15.

15. Pambudi A.S., Moersidik S.S., Karuniasa M. Analysis of recent erosion hazard levels and conservation policy recommendations for Lesti Subwatershed, Upper Brantas Watershed. Jurnal Perencanaan Pembangunan: the Indonesian Journal of Development Planning, 2021, vol. 5, no. 1, pp. 71-93. 
16. Aslam B., Maqsoom A., Alaloul W.S., Musarat M.A., Jabbar T. Zafar A. Soil erosion susceptibility mapping using a GIS-based multi-criteria decision approach: case of district Chitral, Pakistan. Ain Shams Engineering Journal, 2021, vol. 12, no. 2, pp. $1637-1649$.

17. Ghosh A., Maiti R. Soil erosion susceptibility assessment using logistic regression, decision tree and random forest: study on the Mayurakshi river basin of Eastern India. Environmental Earth Sciences, 2021, vol. 80, no. 8, pp. 1-16.

18. Tairi A., Elmouden A., Bouchaou L., Aboulouafa M. Mapping soil erosion-prone sites through GIS and remote sensing for the Tifnout Askaoun watershed, southern Morocco. Arabian Journal of Geosciences, 2021, vol. 14, no. 9, pp. 1-22.

19. Kumar P., Garg V., Mittal S., Murthy Y.K. GIS-based hazard and vulnerability assessment of a torrential watershed. Environment, Development and Sustainability, 2021. Available at: https:// doi.org/10.1007/s10668-021-01476-z (accessed 11 July 2021).

20. Agnihotri D., Kumar T., Jhariya D. Intelligent vulnerability prediction of soil erosion hazard in semi-arid and humid region. Environment, Development and Sustainability: a Multidisciplinary Approach to the Theory and Practice of Sustainable Development, 2021, vol. 23, no. 2, pp. 2524-2551.

21. Abdullahi A.I. Application of Remote Sensing and Geoinformatics Techniques in erosion mapping and groundwater management in the River Amba Watershed, Central Nigeria. Journal of the Nigerian Society of Physical Sciences, 2021, vol. 3, no. 2, pp. 59-65.

22. Teshome A., Halefom A., Teshome M., Ahmad I., Taddele Y., Dananto M., Szucs P. Soil erosion modelling using GIS and revised universal soil loss equation approach: a case study of Guna-Tana landscape, Northern Ethiopia. Modeling Earth Systems and Environment, 2021, vol. 7, no. 1, pp. 125-134.

23. Safwan M., Alaa K., Omran A., Quoc B.P., Nguyen T.T.L., Van N.T. Endre H. Predicting soil erosion hazard in Lattakia Governorate (W Syria). International Journal of Sediment Research, 2021, vol. 36, no. 2, pp. 207-220.

24. Hoseinzadeh M.M., Barkhordari N. Zonation of bank erosion vulnerability (case study: haft Cheshmeh river, Qazvin). Physical Geography Research Quarterly, 2021, vol. 53, no. 1, pp. 123-140.

25. Akbari G., Amani M. Investigation of important and effective factors in soil erosion and sedimentation of Shirin Darreh river using remote sensing and GIS approaches. Iranian journal of Ecohydrology, 2021, vol. 8, no. 1, pp. 283-293.

26. Kolli M.K., Opp C., Groll M. Estimation of soil erosion and sediment yield concentration across the Kolleru Lake catchment using GIS. Environmental Earth Sciences, 2021, vol. 80, no. 4 pp. 1-14.

27. Kumar N., Singh S.K. Soil erosion assessment using earth observation data in a trans-boundary river basin. Natural Hazards, 2021, vol. 107, no. 1, pp. 1-34

28. Batool S., Shirazi S.A., Mahmood S.A. Appraisal of soil erosion through RUSLE model and hypsometry in Chakwal Watershed (Potwar-Pakistan). Sarhad Journal of Agriculture, 2021, vol. 37, no. 2, pp. 594-606.

29. Wang F., Sahana M., Pahlevanzadeh B., Pal S.C., Shit P.K., Piran M.J., Mosavi A. Applying different resampling strategies in machine learning models to predict head-cut gully erosion susceptibility. Alexandria Engineering Journal,2021, vol. 60, no. 6 , pp. 5813-5829.

30. Sharafi S., Kamangir H., King S.A., Safaierad R. Effects of extreme floods on fluvial changes: the Khorramabad River as case study (western Iran). Arabian Journal of Geosciences, 2021, vol. 14 , no. 12 , pp. $1-11$.

31. Getnet T., Mulu A. Assessment of soil erosion rate and hotspot areas using RUSLE and multi-criteria evaluation technique at Jedeb watershed, Upper Blue Nile, Amhara Region, Ethiopia. Environmental Challenges, 2021, vol. 4, no. 8, Article number 100174

32. Ghosh B., Mukhopadhyay S. Erosion susceptibility mapping of sub-watersheds for management prioritization using MCDM-based ensemble approach. Arabian Journal of Geosciences, 2021, vol. 14, no. 1 , pp. $1-18$.

33. Ghosh A., Maiti R. Development of new composite index on channel sensitivity using AHP, FR and ensemble model and its application on the Mayurakshi river of Eastern India. International Journal of River Basin Management, 2021, vol. 80, no. 8, pp. 1-18.
34. Liu H., Liu Y.X., Zhao W.W., Peng D. Soil conservation assessment via climate change and vegetation growth scenarios in the Nile River basin. Journal of Mountain Science, 2021, vol. 18, no. 4, pp. 863-877.

35. Santi P., Manning J., Zhou W., Meza P., Colque P. Geologic hazards of the Ocoña river valley, Peru and the influence of smallscale mining. Natural Hazards, 2021, vol. 108, no. 9, pp. 2679-2700 Available at: https://doi.org/10.1007/s11069-021-04794-7 (accessed 15 June 2021).

36. Gebreegziabher T., Suryabhagavan K.V., Kumar Raghuvanshi T. WebGIS-based decision support system for soil erosion assessment in Legedadi watershed, Oromia Region, Ethiopia. Geology, Ecology, and Landscapes, 2021. AHEAD-OFPRINT. pp. 1-18. Available at: https://doi.org/10.1080/24749508. 2021.1924441 (accessed 11 July 2021).

37. Khademalrasoul A., Amerikhah H. Assessment of soil erosion patterns using RUSLE model and GIS tools (case study: the border of Khuzestan and Chaharmahal Province, Iran). Modeling Earth Systems and Environment, 2021, vol. 7, no. 2, pp. 885-895.

38. Ghorbanzadeh O., Feizizadeh B., Blaschke T. An interval matrix method used to optimize the decision matrix in AHP technique for land subsidence susceptibility mapping. Environmental Earth Sciences, 2018, vol. 77, Article number 584

39. Gudiyangada Nachappa T., Tavakkoli Piralilou S., Ghorbanzadeh O., Shahabi H., Blaschke T. Landslide susceptibility mapping for Austria using Geons and optimization with the Dempster-Shafer theory. Applied Science, 2019, vol. 9 (24), Article number 5393.

40. Gudiyangada Nachappa T., Kienberger S., Meena S.R., Hölbling D., Blaschke T. Comparison and validation of per-pixel and objectbased approaches for landslide susceptibility mapping. Geomatics, Natural Hazards and Risk, 2020, vol. 11, no. 1, pp. 572-600.

41. Guzzetti F., Reichenbach P., Ardizzone F., Cardinali M., Galli M. Estimating the quality of landslide susceptibility models. Geomorphology, 2006, vol. 81, pp. 166-184.

42. Ivanova E. Landslide susceptibility mapping using Frequency Ratio and Analytic Hierarchy Process (AHP): comparative study of two areas in Bulgaria. Proceedings of the International Conference Analysis and Management of Changing Risk for Natural Hazards. Padua, Italy, 18-19 November, 2014. pp. AP23-1-AP23-9.

43. Rasyid A.R., Bhandary N.P., Yatabe R. Performance of frequency ratio and logistic regression model in creating GIS based landslides susceptibility map at Lompobattang Mountain, Indonesia. Geoenvironmental Disasters, 2016, vol. 3, Article number 19.

44. Zhang Y.X., Lan H.X., Li L.P., Wu Y.M, Chen J.H., Tian N.M. Optimizing the frequency ratio method for landslide susceptibility assessment: A case study of the Caiyuan Basin in the southeast mountainous area of China. Journal of Mountain Science, 2020, vol. 17, Article number 2.

45. Zhuang J., Peng J., Zhu X., Li W., Ma P., Liu T. Spatial distribution and susceptibility zoning of geohazards along the Silk Road, Xian-Lanzhou. Environmental Earth Sciences, 2016, vol. 75, Article number 711.

46. Wang M., Qiao J., He S. GIS-based earthquake-triggered landslide hazard zoning using contributing weight model. Journal of Mountain Science, 2010, vol. 7, pp. 339-352. DOI: 10.1007/s11629-010-2054-7.

47. Cheng J., Tao J.P. Fuzzy comprehensive evaluation of drought vulnerability based on the analytic hierarchy process - an empirical study from Xiaogan City in Hubei Province. Agriculture and Agricultural Science Procedia, 2010, vol. 1, pp. 126-135.

48. Yang Z., Li W., Pei Y., Qiao W., Wu Y. Classification of the type of eco-geological environment of a coalmine district: a case study of an ecologically fragile region in Western China. Journal of Cleaner Production, 2018, vol. 174, pp. 1513-1526.

49. Liu $\mathrm{S}$., Li W. Indicators sensitivity analysis for environmental engineering geological patterns caused by underground coal mining with integrating variable weight theory and improved matter-element extension. Science of the Total Environment, 2019, vol. 686 , pp. 606-618.

50. Liu S., Li W., Wang Q. Zoning method for environmental engineering geological patterns in underground coal mining areas. Science of the Total Environment, 2018, vol. 634, pp. 1064-1076. 
51. Strokova L.A., Ezhkova A.V., Leonova A.V. The application of lineament analysis to assess the karst hazard in the design of the main gas pipeline in South Yakutia. Bulletin of the Tomsk Polytechnic University. Geo Assets Engineering, 2020, vol. 331, no. 11, pp. 117-126. In Rus.

52. Strokova L.A. Zoning of construction sites of the settling ponds of the Elginsky coal Deposit in Yakutia. Bulletin of the Tomsk Polytechnic University. Geo Assets Engineering, 2021, vol. 332, no. 1, pp. 97-106. In Rus.

53. Strokova L.A., Dmitrieva S.A. Osmushkina N.V., Osmushkin A.V. Experience of engineering-geological zoning on bearing capacity of soils of the industrial site of Elga coal-preparation plant in Yakutia. Bulletin of the Tomsk Polytechnic University. Geo Assets Engineering, 2019, vol. 330, no. 2, pp. 175-185. In Rus.

54. Strokova L. Recognition of geological processes in permafrost conditions. Bulletin of Engineering Geology and the Environment, 2019, vol. 78, no. 8, pp. 5517-5530.

55. Phi H.T., Strokova L.A. Classification of soil types for Hanoi (Vietnam) when studying land subsidence at groundwater extraction. Bulletin of the Tomsk Polytechnic University. Geo Assets Engineering, 2017, vol. 328, no. 4, pp. 6-17. In Rus.

56. Strokova L.A., Galeeva E.I., Leonova A.V. Zoning of engineeringgeocryological conditions of the pipelines on VostochnoMessoyakhskoye field oil and gas condensate field. Bulletin of the Tomsk Polytechnic University. Geo Assets Engineering, 2020, vol. 331, no. 10, pp. 14-22. In Rus.

57. Strokova L.A., Teterin E. A. Identification, diagnosis and ranking of risks of geohazard in pipeline and urbanized territories. IOP Conference Series: Earth and Environmental Science, 2016, vol. 43, Article number 012051. Available at: http:// iopscience.iop.org/1755-1315/43/1/012051 (accessed 11 July 2021).

58. Strokova L.A. Nadezhdina Yu.Yu. Typification of engineering and geological conditions of the territory of the route of the projected railway Elegest-Kyzyl-Kuragino. Bulletin of the Tomsk Polytechnic University. Geo Assets Engineering, 2020, vol. 331, no. 2, pp. 64-77. In Rus.

59. Strokova L.A., Epifanova E.A., Korzhneva T.G. Numerical analysis of bridge foundation behaviour on the old railway line.
Bulletin of the Tomsk Polytechnic University. Geo Assets Engineering, 2017, vol. 328, no. 5, pp. 125-139. In Rus.

60. Epifanova E.A., Strokova L.A. Evaluation of deformation of a historic building in Tomsk by an Integrated Approach Based on Terrestrial Laser Scanner and Finite Element Modeling. Bulletin of the Tomsk Polytechnic University. Geo Assets Engineering, 2018, vol. 329, no. 5, pp. 27-41. In Rus.

61. Epifanova E.A., Strokova L.A. Numerical analysis of deformations of the lighting mast by ground laser scanning and finite elements method. Bulletin of the Tomsk Polytechnic University. Geo Assets Engineering, 2019, vol. 330, no. 5, pp. $7-$ 17. In Rus.

62. Saharovskij A.V. Strokova L.A. Determining landslide slope stability when designing a bridge over the river Poshnarka in the Chuvash Republic. Bulletin of the Tomsk Polytechnic University. Geo Assets Engineering, 2020, vol. 331, no. 1, pp. 125-134. In Rus.

63. Strokova L.A., Purgina D.V., Galeeva E.I., Kurchatova A.N. Evaluation of engineering-geocryological conditions of the Beregovoe oil and gas condensate field. Bulletin of the Tomsk Polytechnic University. Geo Assets Engineering, 2018, vol. 329, no. 12, pp. 6-19. In Rus.

64. Shikhov A.N., Gerasimov A.P., Ponomarchuk A.I., Perminova E.S Tematicheskoe deshifrirovanie $i$ interpretatsiya kosmicheskikh snimkov srednego $i$ vysokogo prostranstvennogo razresheniya [Thematic decoding and interpretation of satellite images of medium and high spatial resolution]. Perm, Perm State National Research University, 2020, 191 p. Available at: http://www.psu.ru/ files/docs/science/books/uchebnie-posobiya/shikhov-gerasimovponomarchuk-perminova-tematicheskoe-deshifrovanie-iinterpretaciya-kosmicheskih-snimkov.pdf (accessed 15 July 2021).

65. VEGA-RRO sputnikovy servis analiza vegetatsii [Satellite service for vegetation analysis]. Available at: http://sci-vega.ru/maps/ (accessed 27 July 2021).

Received: 30 July 2021.

Information about the authors

Lyudmila A. Strokova, Dr. Sc., professor, National Research Tomsk Polytechnic University. 